\title{
Valuing Urban Bus Attributes: An Experience in Kolkata
}

\author{
C. V. Phanikumar and Bhargab Maitra \\ Indian Institute of Technology, Kharagpur
}

\begin{abstract}
The article presents the marginal willingness-to-pay (WTP) estimates for various qualitative and quantitative attributes of travel with reference to the bus transportation system in Kolkata City, India. A stated choice experiment is designed to capture the responses for estimating marginal WTP values for various attributes. WTP values are estimated separately for commuting and noncommuting trips. The effects of model specification and socioeconomic parameters on WTP values are also studied. Estimates from standard multinomial logit (MNL) and different random parameter logit (RPL) models indicate that WTP values vary with model specification. In the process of developing RPL models, successful application of sparsely used constrained triangular distribution is also demonstrated.
\end{abstract}

\section{Introduction}

Travel needs in developing countries are largely served by public transportation systems, especially bus transportation systems. In the recent years, bus fares have risen at regular intervals due to frequent increases in the price of petroleum fuels all over the world. However, poor quality of travel in bus transportation systems continues, with a resulting declining trend in bus patronage. Policy-makers and practitioners are constantly in search of solutions for improving bus patronage, especially in urban areas of developing countries. 
It is essential to improve the bus patronage in urban areas, not only for minimizing the usage of private vehicles and resulting road congestion, but also to safeguard the environment for greater community benefit. Any improvement is expected to bring some benefits to the users, and estimation of user benefits is an essential input for evaluating any improvement plan. The literature shows evidence of estimation of user benefits in the form of willingness-to-pay (WTP) values in the context of transport and nontransport improvements (Hensher 1994; Jose HolguinVeras 2002; Hensher and Greene 2001; Hensher 2001; Hensher and Sullivan 2003; Adamowicz, Louviere, and Williams 1994; Carlsson, Frykblom and Liljenstolpe 2003; Onyango, Govindasamy, and Nayga 2004). However, most of the studies are carried out in developed countries with limited information available about WTP values in developing countries like India.

In the present study, an attempt is made to estimate WTP values associated with various qualitative and quantitative attributes of bus transportation system with reference to Kolkata City in India. The travel demand in Kolkata City is largely served by more than 5,000 buses. Longer travel times, poor levels of comfort inside buses (based on crowding), poor appearance of buses (both internal and external), and high noise levels are common features of the bus transportation system in Kolkata. Therefore, all these attributes along with travel cost are considered for the estimation of WTP values.

WTP estimates vary depending on the approach and/or model specification adopted. Users' willingness to pay also depends on the trip purpose. In addition, WTP values may also be influenced by one or more sociodemographic parameters such as age, income, household size, etc. The objective of this research is to estimate users' WTP values associated with various attributes of bus transport, and study the variation with different model specifications and trip purposes. Trips are classified as commuting (work and business) and noncommuting (recreation and social), and separate models are developed for estimating WTP values. The effect of socioeconomic characteristics on the mean of random parameter ("mean heterogeneity") is also investigated.

\section{Methodology}

\section{Approach}

To estimate WTP values, it is necessary to develop utility models on the basis of user preferences collected in the form of either Revealed Preference (RP) or 
Stated Preference (SP) data. Both RP and SP data have been used in diverse fields for estimating WTP values (Adamowicz, Louviere, and Williams 1994; Bates 1982; Kroes and Sheldon 1988; Louviere 1988; Hensher 1994; Jose Holguin-Veras 2002). At times, RP data may be inappropriate as they cannot accommodate nonexisting attributes or variability of attributes, which in turn does not permit the establishment of their influences. On the other hand, SP data facilitate inclusion of hypothetical attributes and variability of attributes. Due to the overall poor service quality of buses in Kolkata, the RP data does not include the variability of attributes. Although it is not advised to use stand-alone SP models for predictions, they are rich and effective in estimating marginal WTP values (Hensher and Sullivan 2003). Therefore, SP data is used for the development of the utility model to estimate WTP values.

SP data may be collected in the form of rating, ranking, and choice. The Stated Choice (SC) method has strong theoretical foundations based on economic theory and is an established approach for understanding and predicting consumer trade-offs and choices in marketing research. SC experiments provide a framework where one can study the relative marginal disutility of variations in attributes and their potential correlations (Louviere, Hensher, and Swait 2000). SC methods are extensively used to model the behavior of individuals (Hensher and Greene 2001; Hensher 2001; Hensher and Sullivan 2003; Carlsson, Frykblom and Liljenstolpe 2003; Onyango, Govindasamy, and Nayga 2004). In the present study, the SC method, where profiles generated using various attributes and their levels are presented to the respondent in the form of choice set, is adopted for observing preferences. Responses in the form of "choice" among the presented choice alternatives are utilized to develop utility models and estimate the WTP values.

Generally, SP and/or RP data are analyzed using Multinomial Logit (MNL) models due to simplicity in estimation. However, MNL models impose restrictions such as independence of irrelevant alternatives (IIA). Modifications to the MNL models to reduce the influence of restrictions lead to Random Parameter Logit (RPL) or Mixed Logit (ML). In this article, travelers' marginal WTP values are estimated using SC data and RPL models with constrained triangular distributions over random parameters. RPL models are developed considering uncorrelated choice sets and correlated choice sets across each individual traveler.

\section{Econometric Model}

MNL models are essentially econometric models developed on the basis of Random Utility Theory (Thurstone 1927; McFadden 1974), where the utility of each 
element has an observed (deterministic) component denoted by $V$ and a random (disturbance) component denoted by $\varepsilon$ :

$$
\mathrm{U}=\mathrm{V}+\varepsilon
$$

If the deterministic part $V$ is again a function of the observed attributes $(z)$ of the choice as faced by the individual, the observed socioeconomic attributes of the individual $(S)$ and a vector of parameters $(\beta)$, then

$$
V=V(z, S, \beta)
$$

A probabilistic statement can be made (due to presence of the random component) as, when an individual " $n$ " is facing a choice set, $C_{n}$, consisting of $J_{n}$ choices, the choice probability of alternative $i$ is equal to the probability that the utility of alternative "I," $U_{\text {in }}$ is greater than or equal to the utilities of all other alternatives in the choice set. For example,

$$
\begin{aligned}
& \operatorname{Pn}(i)=\operatorname{Pr}\left(U_{\text {in }} \geq U_{j n^{\prime}}, \text { for all } j \in C_{n}\right) \\
& \operatorname{Pn}(i)=\operatorname{Pr}\left(V_{\text {in }}+\varepsilon_{\text {in }} \geq V_{j n}+\varepsilon_{\text {jn }} \text { for all } j \in C_{n}, j \neq i\right)
\end{aligned}
$$

Assuming IID (Gumbel distribution) for $\varepsilon$, the probability that an individual chooses i can be given by the MNL model (McFadden 1974; Ben-Akiva and Lerman 1985)

$$
P_{n}=\frac{e^{V_{i n}}}{\sum_{j \in j_{n}} e^{V_{i n}}}
$$

This model can be estimated by Maximum Likelihood techniques, and is a useful first cut at modeling choice behavior. However, several well-known limitations apply. The most severe is the IIA property, which states that a change in the attributes of one alternative changes the probabilities of the other alternatives in proportion. This substitution pattern may not be realistic in all settings. Secondly, the coefficients of all attributes are assumed to be the same for all respondents in a choice experiment, whereas in reality there may be substantial variability in how people respond to attributes. To overcome these limitations, a generalized form of MNL (i.e., a random parameters logit model) is used to account for unobserved heterogeneity. Let us assume the utility function of alternative $i$ for individual $n$ is

Uin $=\beta x_{\text {in }}+\varepsilon_{\text {in }}=\beta^{\prime} x_{\text {in }}+\hat{\beta}_{n} x_{\text {in }}+\varepsilon_{\text {in }}$ 
Thus, each individual's coefficient vector $\beta$ is the sum of the population mean $\beta^{\prime}$ and individual deviation $\hat{\beta}_{n} \cdot \beta_{n} x_{\text {in }}$ are error components that induce heteroskedasticity and correlation over alternatives in the unobserved portion of the utility. This means that an important implication of the ML specification is that we do not have to assume that the IIA property holds. Let tastes, $\beta$, vary in the population with a distribution with density $f(\beta \mid \theta)$, where $\theta$ is a vector of the true parameters of the taste distribution. If the error terms $\left(\varepsilon_{\text {in }}\right)$ are IID type I extreme value, it is a random parameter logit model (Train 1998). The conditional probability of observing a sequence of choices is the product of the conditional probabilities

$$
S_{n}\left(\beta_{n}\right)=\prod P\left(k(n, t) t \mid \beta_{n}\right)
$$

where:

$k(n, t) \quad$ denotes the sequence of choices from choice sets that person $n$ chooses in situation $t$

In the choice experiment, the sequence of choices is the number of hypothetical choices each respondent makes in the survey. The unconditional probability for a sequence of choices for individual $\mathrm{n}$ is then expressed as the integral of the conditional probability in (3) over all values of $\beta$ :

$$
P_{n}(\theta)=\int S_{n}(\beta) f(\beta \mid \theta) d \beta
$$

In general, the integral cannot be evaluated analytically, and one has to rely on a simulation method for the probabilities. Here a simulated maximum likelihood estimator, using Halton draws, to estimate the models is used (Train 1999). This type of random parameter model is less restrictive than standard conditional logit models. However, these less restrictive models should be applied cautiously. Apart from being more difficult to estimate, the literature shows that the results can be rather sensitive to the distributional assumptions and the number of draws applied in the simulation (Hensher and Greene 2001). Therefore, the gain in terms of precision of the estimates of WTP is unclear. 


\section{Distributions}

For the development of RPL models, it is necessary to assume suitable distributions for random parameters. Different distributions for random parameters like normal, lognormal, uniform, and triangular have been attempted by researchers while developing RPL models (Algers et al. 1998 ; Hensher 2001; Revelt and Train 1997; Hensher and Greene 2001; Train 2001).

The lognormal distribution is suitable if the mean of random parameter needs to be of specific (nonnegative) sign. However, a long upper tail of lognormal distribution results in extremely high WTP values. A uniform distribution with a $(0,1)$ bound is suitable for dummy variables. The triangular distribution, where the density function looks like a tent with a peak in the center and dropping off linearly on both sides of the center, is advantageous over normal or lognormal distributions due to its bounded nature. However, like normal or uniform distribution, triangular distribution also has the disadvantage of producing the wrong sign to some shares due to spread or standard deviation. It is possible to overcome the disadvantage of triangular distribution by imposing a constraint on the spread. In constrained triangular distribution, mean and spread are made equal to minimize the effect of spread on WTP estimates, yet producing WTP estimates with proper signs (Hensher and Greene, 2001). The advantages of constrained triangular distribution over other distributions are:

1. The bounded nature of the triangular distribution helps in early convergence of the model.

2. It keeps the sign of the estimate the same for all respondents (i.e., there is no reversal of sign throughout the respondents) unlike normal or triangular distributions.

3. It provides simplicity in WTP estimations.

When mean=spread, the impact of the spread is negligible and the ratio of mean to any random parameter (with constrained triangular distribution) over mean of cost will give the WTP value directly. It is not so with normal or triangular distributions, where standard deviation/spread is also to be considered while calculating the WTP value of any random parameter. When mean and spread are made equal, the constrained distribution has a peak in the density function with two endpoints of the distribution fixed at 0 and $2^{*}$ mean, so that there is no free variance (scaling) parameter. Although constrained triangular distribution has several advantages over the other distributions, its application in WTP estimate has not 
been explored adequately. In the present work, the application of constrained triangular distribution is explored while developing RPL models.

\section{Correlations Among Choice Sets}

In stated choice studies, respondents are often asked a series of hypothetical choice questions. For each experiment, a set of alternatives with different attributes/levels is described, and the respondent is asked to state which alternative he/she would choose. A series of such questions is asked, with the attributes of the products varying so as to determine how the respondent's choice changes when the attributes change. In addition, this process also allows researchers to make sure that each respondent gets an opportunity to evaluate several SP alternatives. This process improves the richness of the data but may lead to correlated responses across observations, which is in violation of independence of observations assumption in classical choice model estimation (Hensher and Greene 2001). RPL models are developed in the present work taking into account the correlations among responses across each individual.

\section{Survey Instrument}

Survey instruments are designed for collecting respondent's trip characteristics, socioeconomic characteristics, and stated preference "choice" from the choice set. Six attributes are considered for the design of choice sets. During the preliminary investigation it is observed that the journey speed for buses is considerably low, comfort is less, appearance of buses is poor, and noise level is high. Therefore, the primary attributes of travel speed and travel cost and the secondary attributes of discomfort, waiting time, appearance of bus, and noise level are considered for the preparation of choice sets. Each attribute is further described by suitable levels. Levels are decided following discussions with experts and trip- makers. The attributes and corresponding levels as used in the study are:

- travel speed $(\mathrm{km} / \mathrm{h}): 20,15,12.5,10$

- waiting time (minutes): $4,8,12,16$

- travel (dis)comfort: comfortable seating, congested seating, get seat during journey

- comfortable standing, standing in crowd

- noise level: very low, low, high, very high 
- appearance: good, average, poor

- Travel cost (paise/km): 50, 75,100, 125

The full factorial technique with above-mentioned attributes and levels would produce $4^{4 *} 3^{*} 5$ (3840) combinations/alternatives/profiles. However, it is practically not possible to include all these profiles in the SP experiment. Fractional factorial orthogonal main effects design (by SPSS 7.5) produced 32 alternatives by eliminating the dominating and dominated alternatives. These alternatives are randomly grouped into eight blocks, each containing four SC alternatives and each respondent is asked to choose an alternative from four blocks. Two sets of questionnaires are prepared each having four SP blocks. While presenting the alternatives, travel time and the corresponding travel speed both are presented to respondents for their convenience. For collection of SP responses, enumerators were trained in multiple sessions to improve the quality of the work as these are personal, paper-and-pencil interviews. A sample of the SP choice set is presented in Figure 1.

\section{Figure 1. Sample Choice Set}

\begin{tabular}{|l|c|c|c|c|}
\hline \multirow{2}{*}{ Attribute } & Alternative 1 & Alternative 2 & Alternative 3 & Alternative 4 \\
\cline { 2 - 5 } Travel (dis)comfort & $\begin{array}{c}\text { Standing in } \\
\text { crowd }\end{array}$ & $\begin{array}{c}\text { Get seat during } \\
\text { journey }\end{array}$ & $\begin{array}{c}\text { Congested } \\
\text { seating }\end{array}$ & $\begin{array}{c}\text { Standing } \\
\text { comfortably }\end{array}$ \\
\hline Travel speed (kph) & 12.5 & 20 & 15 & 15 \\
\hline Travel time (min/km) & 5 & 3 & 4 & 4 \\
\hline Waiting time (min) & 4 & 8 & 16 & 12 \\
\hline External appearance & Average & Poor & Average & Good \\
\hline Noise level & Low & High & Very low & Very high \\
\hline Travel cost (paise/km) & 50 & 125 & 100 & 75 \\
\hline
\end{tabular}

Choice 


\section{Database}

Data were collected from Kolkata bus users in October 2004. The study sample was intercepted while they were at shopping centers, recreational places, and at offices spread over the city. Respondents' recent trip characteristics, socioeconomic characteristics, and responses to the choice sets were collected. Every respondent was asked to make a choice among four alternatives presented in each choice set. This was repeated four times so that each respondent gets an opportunity to evaluate 16 SP alternatives. During the study, 1,700 respondents were approached and $1,200(73.5 \%)$ gave their consent. Of the 1,200 respondents, only 1,021 respondents' data were found useful for the development of the models. The remaining data were eliminated due to nonresponses to various items. Information collected included respondent's socioeconomic characteristics (age, occupation, personal income, family members, household income) along with trip characteristics (trip length, cost of recent trip, trip purpose, etc.), and SP choice. Summary statistics of the information about trip purposes and socioeconomic details like gender, age, household income, and car ownership forming the database are given in Table 1.

\section{Model Development}

A total of 3,261 observations were used for the development of models. Models for commuting trips were developed using 853 observations, while 2,048 observations are used for developing models for noncommuting trips. LIMDEP 8.0 (2005) was used for the analysis of SC data using MNL and RPL models. Three RPL models were attempted for each trip purpose-one (RPL 1 ) with independent choice sets, another (RPL 2a) assuming correlations among choice sets across each individual, and the final one (RPL $2 b$ ) considering heterogeneity (i.e., effect of sociodemographic parameters such as age, gender, income, etc.) around the mean of random parameter. In the process of developing models for commuting trips, heterogeneity around mean could not be observed. In RPL models, all the parameters except travel cost are considered random parameters. Travel cost was considered a fixed parameter because (1) it simplifies the estimation of marginal WTP for other parameters (i.e., simple division of coefficient of attribute by coefficient of cost); (2) the distribution of the marginal WTP for an attribute becomes the distribution of that attribute's coefficient; and (3) it ensures the price variable to be nonpositive for all individuals. 
Table 1. Summary Statistics

\begin{tabular}{ll} 
Variable & Number (\%) \\
\hline Total sample & 1,021 \\
Net observations & 3,261 \\
Gender (male) & $2,964(91 \%)$ \\
Age (years) & \\
$\quad<15$ & $8(0.2 \%)$ \\
$15-25$ & $526(16.4 \%)$ \\
$26-40$ & $2,008(61.6 \%)$ \\
$40-60$ & $635(19.4 \%)$ \\
$>60$ & $84(2.4 \%)$ \\
Household income (INR) & \\
$\leq 5000$ & $286(8.7 \%)$ \\
$5,001-10,000$ & $819(25.1 \%)$ \\
$10,001-20,000$ & $1,012(31.1 \%)$ \\
$20,001-30,000$ & $996(30.6 \%)$ \\
$>30,000$ & $148(4.5 \%)$ \\
Trip purpose & \\
Work & $1,759(54.0 \%)$ \\
Business & $649(20.0 \%)$ \\
Recreation & $853(26.0 \%)$ \\
Car ownership & \\
0 car & $2,855(87.5 \%)$ \\
1 car & $386(11.8 \%)$ \\
2 cars & $20(0.6 \%)$
\end{tabular}

In the process of developing models, the attributes were coded according to their levels. Quantitative attributes for travel time, waiting time, and travel cost were entered in cardinal linear form (i.e., continuous scale), while qualitative attribute levels were effects coded $(-1,0,1)$. In RPL models, all random parameters are assumed to follow constrained triangular distribution. RPL models are estimated with simulated maximum likelihood using intelligent Halton draws with 200 replications (Train 1999). Initially all attributes and effects-coded variables are considered for model estimation. However, in the initial runs one level (i.e., "congested seating"') of the attribute travel comfort and one level (i.e., "average appearance") of the attribute appearance were found to be insignificant. Therefore, models were reestimated excluding the insignificant levels of attributes (Hensher, Rose 
and Greene 2005). Model estimates for commuting and noncommuting trips are presented in Tables 2 and Table 3, respectively.

\section{Table 2. Coefficient Estimates from MNL and RPL Models for Commuting Trips}

\begin{tabular}{|c|c|c|c|}
\hline \multirow{3}{*}{ Attribute } & \multirow{2}{*}{$M N L$} & \multicolumn{2}{|c|}{ RPL (Constrained Triangular) } \\
\hline & & RPL 1 & RPL 2a \\
\hline & Coefficient & Coefficient & Coefficient \\
\hline \multicolumn{4}{|l|}{ Random parameter means } \\
\hline In-vehicle travel time & $-0.243(7.38)$ & $-0.263(7.52)$ & $-0.277(5.59)$ \\
\hline Waiting time & $-0.101(15.23)$ & $-0.107(14.53)$ & $-0.110(14.56)$ \\
\hline Comfortable seating & $0.234(4.22)$ & $0.256(4.48)$ & $0.247(4.27)$ \\
\hline Get seat enroute & $0.175(2.87)$ & $0.201(3.19)$ & $0.203(3.34)$ \\
\hline Comfortable standing & $-0.126(1.85)$ & $-0.151(2.16)$ & $-0.144(2.08)$ \\
\hline Very low noise & $0.428(7.77)$ & $0.424(7.61)$ & $0.417(7.45)$ \\
\hline Low noise & $0.378(5.44)$ & $0.355(5.13)$ & $0.348(5.14)$ \\
\hline High noise & $-0.364(4.51)$ & $-0.318(4.06)$ & $-0.307(4.06)$ \\
\hline Good appearance & $0.148(4.12)$ & $0.168(4.73)$ & $0.166(4.75)$ \\
\hline \multicolumn{4}{|l|}{ Nonrandom parameters } \\
\hline Travel cost & $-0.033(23.47)$ & $0.034(23.32)$ & $-0.034(23.34)$ \\
\hline \multicolumn{4}{|l|}{ Random parameter spread } \\
\hline In-vehicle travel time & - & $0.263(7.52)$ & $0.277(5.59)$ \\
\hline Waiting time & - & $0.107(14.53)$ & $0.110(14.56)$ \\
\hline Comfortable seating & - & $0.256(4.48)$ & $0.247(4.27)$ \\
\hline Get seat enroute & - & $0.201(3.19)$ & $0.203(3.34)$ \\
\hline Comfortable standing & - & $0.151(2.16)$ & $0.144(2.08)$ \\
\hline Very low noise & - & $0.424(7.61)$ & $0.417(7.45)$ \\
\hline Low noise & - & $0.355(5.13)$ & $0.348(5.14)$ \\
\hline High noise & - & $0.318(4.06)$ & $0.307(4.06)$ \\
\hline Good appearance & - & $0.168(4.73)$ & $0.166(4.75)$ \\
\hline $\begin{array}{l}\text { Heterogeneity in mean } \\
\text { In-vehicle travel time: } \\
\text { Household income }\end{array}$ & - & - & - \\
\hline Observations & 2408 & 2408 & 2408 \\
\hline Log likelihood & -2450.82 & -2452.25 & -2447.59 \\
\hline$\rho^{2}$ & 0.232 & 0.231 & 0.233 \\
\hline
\end{tabular}


Table 3. Coefficient Estimates from MNL and RPL Models for Noncommuting Trips

\begin{tabular}{|c|c|c|c|c|}
\hline \multirow{3}{*}{ Attribute } & \multirow{2}{*}{ MNL } & \multicolumn{3}{|c|}{ RPL (Constrained Triangular) } \\
\hline & & RPL 1 & $R P L 2 a$ & $R P L 2 b$ \\
\hline & Coefficient & Coefficient & Coefficient & Coefficient \\
\hline \multicolumn{5}{|l|}{ Random parameter means } \\
\hline In-vehicle travel time & $-0.256(4.69)$ & $-0.277(4.76)$ & $-0.288(4.78)$ & $-0.437(4.27)$ \\
\hline Waiting time & $-0.096(8.60)$ & $-0.102(8.26)$ & $-0.105(8.29)$ & $-0.101(8.13)$ \\
\hline Comfortable seating & $0.268(2.89)$ & $0.289(3.02)$ & $0.282(2.94)$ & $0.290(3.01)$ \\
\hline Get seat en-route & $0.183(1.78)$ & $0.210(1.98)$ & $0.210(2.06)$ & $0.208(1.95)$ \\
\hline Comfortable standing & $-0.199(1.68)$ & $-0.228(1.86)$ & $-0.224(1.83)$ & $-0.223(1.82)$ \\
\hline Very low noise & $0.468(5.07)$ & $0.465(4.97)$ & $0.455(4.88)$ & $0.462(4.96)$ \\
\hline Low noise & $0.369(3.15)$ & $0.352(3.02)$ & $0.342(3.01)$ & $0.350(2.99)$ \\
\hline High noise & $-0.361(2.66)$ & $-0.320(2.41)$ & $-0.303(2.42)$ & $-0.322(2.43)$ \\
\hline Good appearance & $0.163(2.67)$ & $0.180(2.99)$ & $0.177(3.05)$ & $0.184(3.04)$ \\
\hline \multicolumn{5}{|l|}{ Nonrandom parameters } \\
\hline Travel cost & $-0.032(13.94)$ & $-0.033(13.85)$ & $-0.034(13.93)$ & $-0.033(13.81)$ \\
\hline \multicolumn{5}{|l|}{ Random parameter spread } \\
\hline In-vehicle travel time & - & $0.277(4.76)$ & $0.288(4.78)$ & $0.437(4.27)$ \\
\hline Waiting time & - & $0.102(8.26)$ & $0.105(8.29)$ & $0.101(8.13)$ \\
\hline Comfortable seating & - & $0.289(3.02)$ & $0.282(2.94)$ & $0.290(3.01)$ \\
\hline Get seat enroute & - & $0.210(1.98)$ & $0.210(2.06)$ & $0.208(1.95)$ \\
\hline Comfortable standing & - & $0.228(1.86)$ & $0.224(1.83)$ & $0.223(1.82)$ \\
\hline Very low noise & - & $0.465(4.97)$ & $0.455(4.88)$ & $0.462(4.96)$ \\
\hline Low noise & - & $0.352(3.02)$ & $0.342(3.01)$ & $0.350(2.99)$ \\
\hline High noise & - & $0.320(2.41)$ & $0.303(2.42)$ & $0.322(2.43)$ \\
\hline Good appearance & - & $0.180(2.99)$ & $0.177(3.05)$ & $0.184(3.04)$ \\
\hline \multicolumn{5}{|l|}{ Heterogeneity in mean } \\
\hline $\begin{array}{l}\text { In-vehicle travel time: } \\
\text { Household income }\end{array}$ & - & - & - & $0.212(2.00)$ \\
\hline Observations & 853 & 853 & 853 & 853 \\
\hline Log likelihood & -866.94 & -867.35 & -866.15 & -865.11 \\
\hline$\rho^{2}$ & 0.232 & 0.232 & 0.233 & 0.234 \\
\hline
\end{tabular}

\section{Results and Discussions}

In Tables 2 and Table 3, the signs of the parameter estimates are as expected and in agreement with the actual condition of the study route. It is evident from the $\mathrm{t}$-ratios that the parameter estimates are statistically significantly different from 0 . The overall goodness of fit is considered using Pseudo $R^{2}\left(\rho^{2}\right)$. Value of the $\rho^{2}$ 
between 0.2 and 0.4 indicates acceptable model fit (Louviere, Hensher, and Swait 2000). The $\rho^{2}$ values indicate that these models are good in fit.

The $\rho^{2}$ value is also improved from MNL to RPL with uncorrelated choice sets models and to RPL with correlated choice sets models indicating superior model fit. Parameter estimates from Tables 2 and 3 clearly indicate that in addition to invehicle travel time and waiting time, the discomfort level, appearance, and noise level also have significant effect on use of the service. Often these attributes are ignored while formulating improvement proposals. The negative signs associated with quantitative attributes indicate that use of the service decreases with an increase in the value of in-vehicle travel time and waiting time.

The interpretation of model coefficients is not straightforward except for signifcance. Therefore, the marginal rates of substitution between attributes and cost are calculated. These substitution rates (ratios between coefficient of attribute/ level and coefficient of cost) can be interpreted as marginal WTP for a unit change for continuous attributes. In the case of effects-coded qualitative attributes, estimation of WTP values is based on rescaled coefficients of the levels where the last level is considered the reference level (made equal to 0 ) and the estimated values are with reference to the last level (i.e., for a shift from last level to the level under consideration). While standing in a crowed vehicle is taken as a reference level for the attribute "travel discomfort," very high noise is taken as reference level for the attribute "noise." For the attribute "appearance," poor appearance is taken as the reference level. The marginal WTP estimates for various attributes/levels as obtained from MNL and RPL models are shown in Tables 4 and 5 for commuting and noncommuting trips, respectively.

Table 4 shows the WTP values for commuting trips from different model specifications. The WTP value of in-vehicle travel time ranges from 7.35 paise/min or INR $4.4(\approx 0.10$ USD) per hour to 8.13 paise/min or INR 4.87 ( $\approx 0.11$ USD) per hour. The WTP value for the waiting time ranges from 3.08 paise $/ \mathrm{min}$ to $3.23 \mathrm{paise} / \mathrm{min}$. Table 5 shows the WTP values for noncommuting trips from different model specifications. The value of in-vehicle travel time ranges from 6.62 paise/min or INR 4 $(\approx 0.175$ USD) per hour for the income group with household monthly income less than INR 20000 ( $\approx 455$ USD) to 12.9 paise/min or INR $7.74(\approx 0.175$ USD) per hour for the income group with household monthly income more than INR $20000(\approx$ 455 USD). The WTP value for the waiting time ranges from 2.96 paise $/ \mathrm{min}$ to 3.11 paise/min. WTP values for in-vehicle travel time obtained from the present study are comparable with those reported by other studies in developing countries. The 
Table 4. WTP Values for Commuting Trips

\begin{tabular}{|l|c|r|r|r|}
\hline \multirow{2}{*}{ Attribute } & \multirow{2}{*}{ Unit } & \multicolumn{3}{c|}{ WTP } \\
\cline { 3 - 5 } & Paise $/$ MNin & 7.35 & 7.79 & \multicolumn{1}{c|}{ RPL 1 } \\
\hline $\begin{array}{l}\text { In-vehicle } \\
\text { travel time }\end{array}$ & Paise $/ \mathrm{min}$ & 3.07 & 3.18 & 3.23 \\
\hline Waiting time & Paise $/ \mathrm{km}$ & 15.66 & 16.64 & 16.27 \\
\hline $\begin{array}{l}\text { Comfortable } \\
\text { seating }\end{array}$ & Paise $/ \mathrm{km}$ & 13.89 & 15.01 & 14.97 \\
\hline $\begin{array}{l}\text { Get seat } \\
\text { en-route }\end{array}$ & Paise $/ \mathrm{km}$ & 4.76 & 4.56 & 4.75 \\
\hline $\begin{array}{l}\text { Comfortable } \\
\text { standing }\end{array}$ & Paise $/ \mathrm{km}$ & 26.34 & 26.28 & 25.71 \\
\hline $\begin{array}{l}\text { Very low noise } \\
\text { Low noise }\end{array}$ & Paise $/ \mathrm{km}$ & 24.84 & 24.23 & 23.68 \\
\hline $\begin{array}{l}\text { High noise } \\
\text { Good } \\
\text { appearance }\end{array}$ & Paise $/ \mathrm{km}$ & 2.35 & 4.24 & 4.43 \\
\hline
\end{tabular}

${ }^{*}$ 100paise $=1$ Indian Rupee (INR) and 44 INR=1 US\$

Table 5. WTP Values for Noncommuting Trips

\begin{tabular}{|c|c|c|c|c|c|}
\hline \multirow{2}{*}{ Attribute } & \multirow{2}{*}{ Unit } & \multicolumn{4}{|c|}{ WTP } \\
\hline & & $M N L$ & RPL 1 & RPL 2a & $R P L 2 b$ \\
\hline $\begin{array}{l}\text { In-vehicle } \\
\text { travel time }\end{array}$ & Paise $* / m i n$ & 7.90 & 8.41 & 8.47 & $6.62 / 12.90^{* *}$ \\
\hline Waiting time & Paise /min & 2.96 & 3.09 & 3.08 & 2.98 \\
\hline $\begin{array}{l}\text { Comfortable } \\
\text { seating }\end{array}$ & Paise /km & 16.04 & 17.02 & 16.20 & 16.69 \\
\hline $\begin{array}{l}\text { Get seat } \\
\text { en-route }\end{array}$ & Paise /km & 13.42 & 14.62 & 14.08 & 14.28 \\
\hline $\begin{array}{l}\text { Comfortable } \\
\text { standing }\end{array}$ & Paise /km & 1.65 & 1.35 & 1.30 & 1.56 \\
\hline Very low noise & Paise /km & 29.08 & 29.17 & 27.93 & 28.11 \\
\hline Low noise & Paise /km & 26.03 & 25.75 & 24.59 & 24.79 \\
\hline High noise & Paise /km & 3.51 & 5.38 & 5.63 & 4.98 \\
\hline $\begin{array}{l}\text { Good } \\
\text { appearance }\end{array}$ & Paise /km & 10.04 & 10.94 & 10.42 & 10.84 \\
\hline
\end{tabular}

*100paise $=1$ Indian Rupee (INR) and 44 INR=1 US\$, **For household income more than INR 20000 
WTP values for in-vehicle travel time as reported for Bangladesh, Tanzania, and Ghana are $0.06 \mathrm{USD} / \mathrm{hr}, 0.18 \mathrm{USD} / \mathrm{hr}$ and $0.18 \mathrm{USD} / \mathrm{hr}$, respectively (I.T. Transport 2005). The WTP for in-vehicle travel time as reported for Mumbai (India) bus users is $0.28 \mathrm{USD} / \mathrm{hr}$ (MMPG 1997).

Very low noise (WTP in the range of 25.7 paise $/ \mathrm{km}$ to 26.3 paise $/ \mathrm{km}$ ) is valued almost 3 times as much as good appearance (WTP in the range of 8.99 paise $/ \mathrm{km}$ to 9.77 paise $/ \mathrm{km}$ ), and comfortable seating (WTP in the range of 15.66 paise $/ \mathrm{km}$ to 16.64 paise $/ \mathrm{km}$ ) is valued nearly 1.5 times than good appearance by commuting trip-makers. Similarly, noncommuting trip-makers also valued very low noise (WTP in the range of 27.93 paise $/ \mathrm{km}$ to 29.17 paise $/ \mathrm{km}$ ) about 3 times as much as good appearance (WTP in the range of 10.04 paise $/ \mathrm{km}$ to 10.94 paise $/ \mathrm{km}$ ) and comfortable seating (WTP in the range of 16.04 paise $/ \mathrm{km}$ to 17.02 paise $/ \mathrm{km}$ ) nearly 1.6 times than good appearance. Tables 4 and Table 5 show that there is a big leap in WTP values between high noise to low noise, and between comfortable standing to get seat en-route. Not surprisingly, levels of the attribute "noise" carry high WTP values across qualitative attributes, which closely map the current noise levels in buses. Marginal WTP for in-vehicle travel time is nearly 2.5 times than that for waiting time. High WTP values for qualitative attributes not only indicate the importance of these attributes but also reflect the poor quality of services being offered now. Across MNL and RPL models, these is a little gain in WTP values for all the attributes and levels except for levels very low noise, low noise, and comfortable standing from RPL models. Similar observations with gains in some attributes and loss in others are reported by Train (1998) for recreational demand, Revelt and Train (1999) in household appliance study, Bhat (1998) in mode choice modeling, Algers et al. (1998) while estimating value of travel time, Carlsson (1999) while estimating value of travel time for business class, and Alpizar and Carlsson (2001) in mode choice modeling.

A comparison of WTP estimates between commuting and noncommuting trips indicates that WTP values are sensitive to trip purpose. While commuting tripmakers have higher WTP values for some attributes/levels, noncommuting tripmakers generally have higher WTP values for qualitative attributes. In addition, heterogeneity around the mean of the in-vehicle travel time indicates that the WTP for in-vehicle travel time is more for noncommuting trips made by the highincome group.

WTP estimates indicate that MNL models in this case marginally underestimated the benefits that can be derived from travel time and waiting time. In general, 
a comparison of estimates from a standard logit and a random specification depends on the data and the assumed distribution for random parameters.

An interesting observation from the estimates is that in all the three estimates the travel time is valued higher than waiting time, unlike in developed countries. This high value of travel time may be attributed to the poor comfort conditions inside the vehicles and longer journey periods. A similar observation is reported by Mumbai Metro Study (1997) for bus users in Mumbai (India). The findings outlined in this article may be helpful while estimating the marginal WTP values for other cities of developing countries.

\section{Conclusions}

Users willingness to pay for various quantitative and qualitative attributes of bus transportation system is estimated with reference to a case study in Kolkata, India. It is found that apart from quantitative attributes, the urban bus user's choice is also influenced by qualitative attributes. This emphasizes the need for considering qualitative attributes while formulating improvement proposals and estimating user benefits in developing countries. The effect of model specification on WTP estimates is studied. For some attributes, the WTP estimates obtained from standard MNL are found lower than those from RPL models. However, for other attributes, RPL models produced lower WTP estimates than MNL models. WTP values are also estimated separately for commuting and noncommuting trips. The noncommuting trip-maker's WTP values are generally high for qualitative attributes. While studying the effect of socioeconomic attributes on WTP values, WTP is shown to be higher for noncommuting trips made by the high-income group.

The article also demonstrates the development of acceptable RPL models with constrained triangular distribution for random parameters. Though constrained triangular distribution has several advantages over other distributions, its application is not explored widely by researchers in RPL model development. The present application is expected to encourage the use of constrained triangular distribution as an alternative to other commonly used distributions while developing RPL models. Though contextual, the findings of the article may be used by planners and policy-makers to formulate strategies for improvement of urban bus transportation system in developing countries. 


\section{Acknowledgments}

The work presented in this article is based on the research project sponsored by the Department of Science and Technology (DST), Ministry of Science and Technology, Government of India. Suggestions from John Rose (ITLS, Sydney) are greatly acknowledged.

\section{References}

Adamowicz, W. L., J. Louviere, and M. Williams. 1994. Combining stated and revealed preference methods for valuing environmental amenities. Journal of Environmental Economics and Management 26: 271-292.

Algers, S., P. Bergström, M. Dahlberg, and J. L. Dillen. 1998. Mixed logit estimation of the value of travel time. Working Paper, Department of Economics, Upsala University.

Alpizar, F., and F. Carlsson. 2001. Policy implications and analysis of the determinants of travel mode choice: An application of choice experiments to metropolitan Costa Rica. Working Paper in Economics 56. Department of Economics, Göteborg University.

Bates, J. 1982. Stated preference technique for the analysis of transportation behavior. In Proceedings of World Conference of Transportation Research. Hamburg, W. Germany: 252-265.

Ben-Akiva, M., and S. R. Lerman. 1985. Discrete choice analysis: Theory and applications to travel demand. Cambridge: MIT Press.

Bhat, C. 1998. Accommodating variations in responsiveness to level-of-service measures in travel mode choice modeling. Transportation Research 32A: 495-507.

Carlsson, F. 1999. The demand for intercity public transport: The case of business passengers. Working Paper, Department of Economics, Göteborg University.

Carlsson, F., P. Frykblom, and C. Liljenstolpe. 2003. Valuing wetland attributes: An application of choice experiments. Ecological Economics 47: 95-103.

Hensher, D. A. 1994. Stated preference analysis of travel choices: The state of practice. Transportation 21(2): 107-133. 
Hensher, D. A. 2001. The valuation of commuter travel time savings for car drivers in New Zealand: Evaluating alternative model specifications. Transportation 28: 101-118.

Hensher, D. A., J. Rose, and W. Greene. 2005. Applied choice analysis-A primer. Cambridge University Press.

Hensher, D. A., and W. H. Greene. 2001. The mixed logit model: The state of practice and warnings for the unwary. Working Paper, School of Business, The University of Sidney.

Hensher, D. A., and C. Sullivan. 2003. Willingness to pay for road curviness and road type. Transportation Research Part D 8: 139-155.

I.T. Transport. 2005. The value of time in least developed countries: The African studies. Unpublished report, I.T Transport Ltd., United Kingdom.

Jose Holguin-Veras, P. E. 2002. Revealed preference analysis of commercial vehicle choice process. Journal of Transportation Engineering 128 (4): 236-346.

Kroes, E. P., and R. J. Sheldon. 1988. Stated preference methods: an introduction. Journal of Transport Economics and Policy 22: 11-25.

LIMDEP 8.0 Reference Guide. (2002). Econometrics Software Inc.

Louviere, J. J. 1988. Conjoint analysis modeling of stated preferences: A review of theory, methods, recent developments and external validity. Journal of Transport Economics and Policy 22(1): 93-119.

Louviere, J. J., D. A. Hensher, and D. J. Swait. 2000. Stated choice methods. Analysis and applications. Cambridge University Press.

McFadden, D. 1974. Conditional logit analysis of qualitative choice behavior. In P. Zarembka, ed., Frontiers in Econometrics. New York: Academic Press, $105-142$.

Mumbai Metro Planning Group. 1997. Mumbai metro study: Travel demand forecasting model. Working Paper No. 4, Mumbai.

Onyango, Benjamin, Ramu Govindasamy and Rodolfo M. Nayga, Jr. 2004. Measuring U.S. consumer preferences for genetically modified foods using choice modeling Experiments: The role of price, product benefits and technology. Paper prepared for presentation at the American Agricultural Economics Association Annual Meeting, Denver, Colorado, August 2004. 
Revelt, D., and K. Train. 1997. Mixed logit with repeated choices: Households' choices of appliance efficiency level. Working Paper, Department of Economics University of California at Berkeley.

Thurstone, L. L. 1927. A law of comparative judgment. Psychological Review 4: 273-286.

Train, K. 1998. Recreation demand models with taste differences over people. Land Economics: 230-239.

Train, K. 1999. Halton sequences for mixed logits. Working Paper, Department of Economics University of California at Berkeley.

Train, K. 2001. A comparison of hierarchical Bayes and maximum simulated likelihood for mixed logit. Working Paper, Department of Economics, University of California at Berkeley.

\section{About the Authors}

C.V. Phanikumar (phani@civil.iitkgp.ernet.in) is a research scholar in transportation engineering in the Department of Civil Engineering at Indian Institute of Technology, Kharagpur, India. His research interests include transport economics, transport planning, and framing-related policy issues using behavioral analysis. He has experience in geometric design of highways and traffic engineering.

BHARGAB MAITRA (bhargab@civil.iitkgp.ernet.in) obtained his Ph. D from IIT, Bombay, India, and is presently an assistant professor in transportation engineering in the Department of Civil Engineering at Indian Institute of Technology, Kharagpur. His research interests include traffic management, operation and maintenance, congestion modeling, and improving public transport systems using behavioral analysis. He has published numerous papers in both national and international journals. 